\title{
Correction to: Effects of Recycled Powder on Solidification Defects, Microstructure, and Corrosion Properties of DMLS Fabricated AISi10Mg
}

\author{
M. RAFIEAZAD ${ }^{10},{ }^{1,2}$ A. CHATTERJEE,${ }^{1}$ and A.M. NASIRI ${ }^{1}$ \\ 1.-Faculty of Engineering and Applied Science, Memorial University of Newfoundland, St. \\ John's, NL A1B 3X5, Canada. 2.—e-mail: mrafieazad@mun.ca
}

\section{Correction to: JOM}

https://doi.org/10.1007/s11837-019-03552-2

The original version of this article was updated to correct an errant space in AlSi10Mg throughout the text. 